LAWRENCE LIVERMORE NATIONAL LABORATORY
Evaluation of Filter Recovery Efficiency for Collection of Engineered Aerosol Test Particles

E. W. Reed

August 8, 2012 
This document was prepared as an account of work sponsored by an agency of the United States government. Neither the United States government nor Lawrence Livermore National Security, LLC, nor any of their employees makes any warranty, expressed or implied, or assumes any legal liability or responsibility for the accuracy, completeness, or usefulness of any information, apparatus, product, or process disclosed, or represents that its use would not infringe privately owned rights. Reference herein to any specific commercial product, process, or service by trade name, trademark, manufacturer, or otherwise does not necessarily constitute or imply its endorsement, recommendation, or favoring by the United States government or Lawrence Livermore National Security, LLC. The views and opinions of authors expressed herein do not necessarily state or reflect those of the United States government or Lawrence Livermore National Security, LLC, and shall not be used for advertising or product endorsement purposes.

This work performed under the auspices of the U.S. Department of Energy by Lawrence Livermore National Laboratory under Contract DE-AC52-07NA27344. 
DHS HS-STEM Essay

$8 / 10 / 12$

\section{Evaluation of Filter Recovery Efficiency for Collection of Engineered Aerosol Test Particles}

\section{Internship Project and Specific Role}

This summer I contributed to a larger project of generating and quantifying aerosol test particles. The purpose of these particles is to simulate any particle that can be aerosolized to model the behavior of aerosols in a particular setting. To do this safely in an environment that may potentially contain inhabitants either immediately or in the future, the particles must be harmless. Additionally, the particles must be unique and identifiable in order to be accurately tracked. To achieve this goal the researchers working on the project embedded non-coding DNA templates of approximately 100 base pairs into sugar crystals. These characteristics make these novel particles safe, biodegradable and customizable so that they may be tested in populated environments, such as office buildings. Various DNA templates can be mixed with the sugar in order to create multiple sets of particles that are each uniquely identifiable. This can be useful in simulating multiple aerosols in the same location. Additionally, fluorophores can be added to the aerosol particles if fluorescence is desired during the particle identification process. The ingredients used to make the aerosol test particles are all kosher certified and FDA approved food additives. Particle generation was initially done with a modified commercially available inkjet printer however, more recently it has been performed with a spray dryer. Collection of the aerosolized test particles can be accomplished by air filtration. The DNA template and sugar compound can then be eluted from the filter and quantification of the DNA template copies can be determined using real-time 
quantitative polymerase chain reaction (qPCR). The number of DNA copies

determined using qPCR will be correlated with the number of aerosol test particles collected. An overview of the entire process is illustrated in Figure 1 below.

Figure 1: Overview of aerosol test particle generation, potential use and quantification.

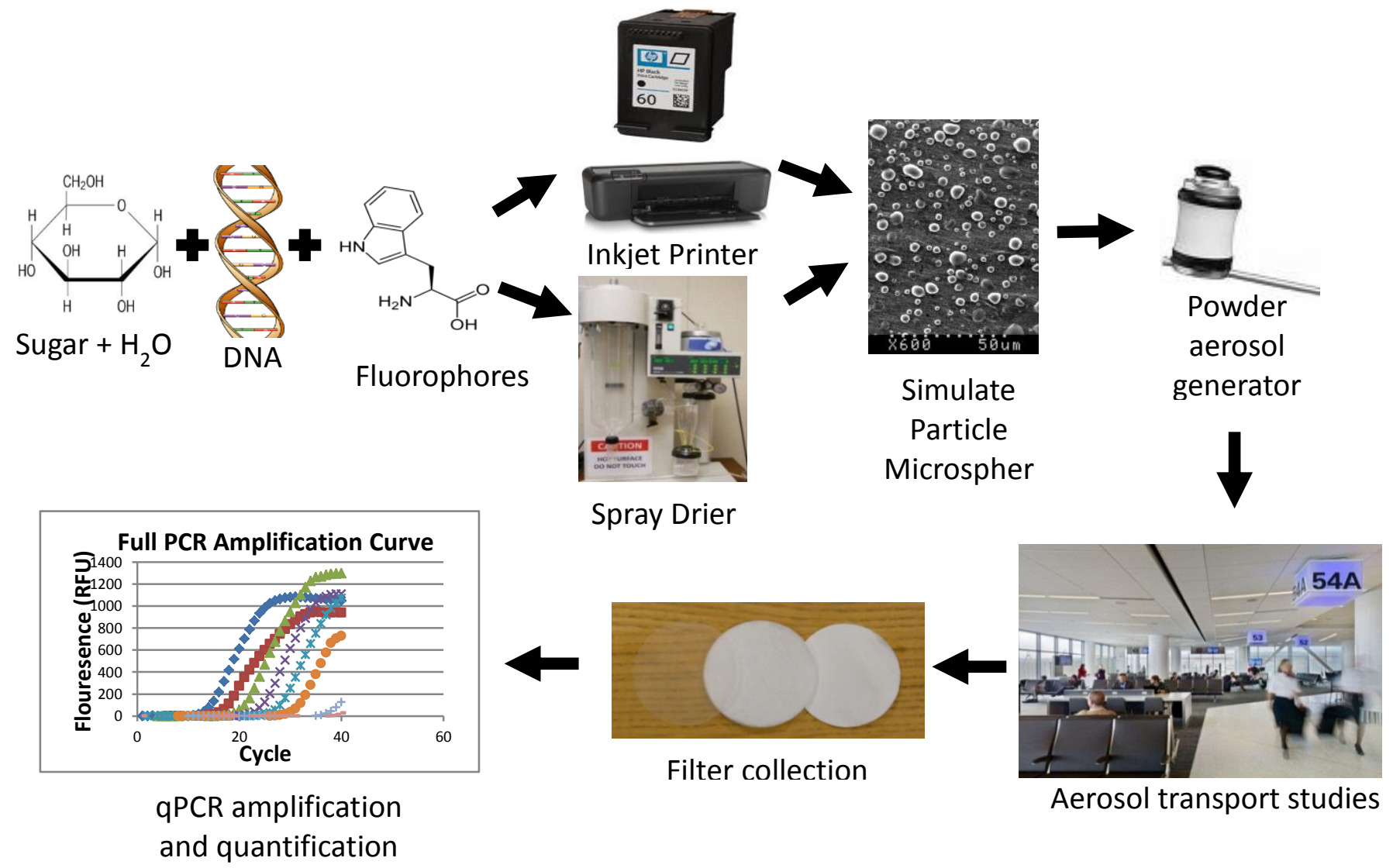

Future work will include the aerosolization of these novel particles, some of which will then be captured by either an automated or manual air filtration process. In order to accurately quantify the amount of aerosol particles picked up during some filtration process, the amount of DNA that is retained by a particular filter must be known. My specific role in the project was the quantification of filter extraction efficiency for the DNA template. The sugar molecules that are attached to the DNA dissolve when in solution, therefore only the DNA directly on the filter needed testing for retention. The 
quantification process involves eluting the DNA from the filter into a buffer and then amplifying and quantifying it using QPCR. My goal was to measure the amount of DNA that could be eluted from a given filter, described as the filter extraction efficiency.

\section{Personal Achievements and Contributions}

My contributions to the project will be explained by the methods used to conduct this experiment of DNA extraction from the three filter types. More of my contributions will be described in the "New Skills and Knowledge" section. Additionally, achievements will be discussed in the "Project Results" section.

\section{Methods}

I tested 3 different common filter types for their extraction efficiency using our specific DNA templates. All three filter types had the same pore size and external diameter and were designed for collecting aerosols (Table 1). The major difference between the filters was their composition: glass fiber, polyester felt and Teflon.

Table 1. Specifications of aerosol filters used during DNA recovery tests.

\begin{tabular}{ccccc}
\hline \multicolumn{5}{c}{ Filter Specifications } \\
\hline Filters Tested & Diameter $(\mathrm{cm})$ & Thickness $(\mu \mathrm{m})$ & Pore Size $(\mu \mathrm{m})$ & Manufacturer \\
Teflon & 4.7 & 165 & 1 & Pall Life Sciences \\
Glass Fiber & 4.7 & 330 & 1 & Pall Life Sciences \\
Polyester Felt & 4.7 & 3000 & 1 & Lockheed Martin \\
\hline
\end{tabular}

A schematic of the filter extraction process can be seen in Figure 2. First, the concentrated DNA template was diluted in PCR grade water. The diluted DNA was used

Figure 2: Filter extraction process

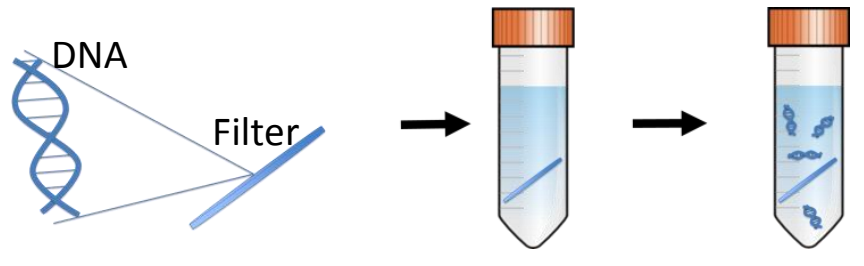

to simulate a reasonable mass of DNA that may be collected on a filter. The three tested simulated masses of collected particles (which would 
contain both DNA and sugar) were $10 \mu \mathrm{g}, 100 \mu \mathrm{g}$ and $1 \mathrm{mg}$. A set volume of $100 \mu \mathrm{L}$ of DNA simulation solution was placed onto one of the test filters. The test filter was place in a tube containing $10 \mathrm{~mL}$ of $0.1 \%$ Triton in PBS buffer. The buffer served the purpose of eluting the DNA from the filter and solvating it. In other applications, Triton in PBS is used as a cell lysis buffer ${ }^{1}$. This is relevant as our aerosol test particles may potentially be used to model intact cells, which would require lysis in order to be quantified by their DNA. As a positive control used for comparison, an equivalent volume of the DNA simulation solution was added directly to a tube of $10 \mathrm{~mL}$ of $0.1 \%$ Triton in PBS buffer without a filter present. A negative control containing no DNA was also tested to insure that no contamination had occurred. The tubes were shaken and vortexed to elute DNA and ensure homogeneity. The contents of the tube were then serially diluted in PCR grade water in order to reduce any inhibitory effects of the buffer solution. The dilutions were then run in qPCR. qPCR is a process used to amplify and quantify DNA. PCR is theoretically an exponential amplification process such that in a perfectly efficient reaction, the concentration of DNA is doubled with each cycle of temperature (Figure 3). The amount of DNA can be quantified

Figure 3: Basic principles of PCR
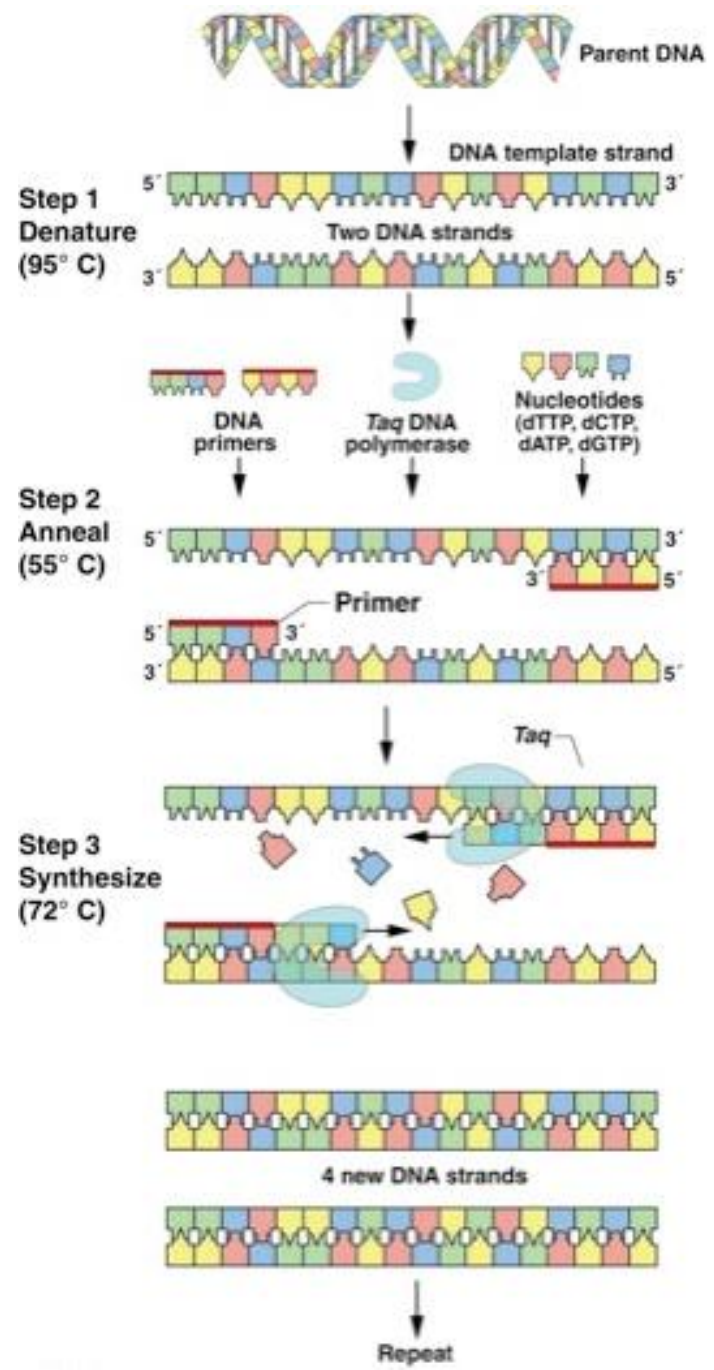
by using a fluorescent probe. The probe is a strand of DNA that has a fluorescent reporter and fluorescence quencher attached to it giving the probe a low background fluorescence. The base sequence of the probe is specific so it can only bind to a specific site on the target DNA. During the annealing stage of the PCR reaction, the primers and probe anneal to the DNA target. The enzyme, Taq Polymerase, begins to polymerize a new DNA strand starting at the primers. It proceeds through the site of the probe, disassembling the probe as moves along the DNA strand. This separates the fluorescent reporter from the quencher, increasing the amount of fluorescence each time a probe is disassembled. The direct correspondence between the increase in fluorescence and the increase in DNA allows us to quantify the amount of DNA replicated. As the reaction proceeds, the relative fluorescence passes a certain cycle threshold $\left(C_{t}\right)$ above the background fluorescence. By comparing the $C_{t}$ of the unknown amount of DNA to known concentrations in a calibration curve, we can calculate the amount of DNA present in the unknown.

\section{$\underline{\text { Achievements and Project Results }}$}

The results of the study showed that for all three filters eluted in $0.1 \%$ Triton in PBS buffer, DNA recovery was approximately $100 \%$ (Table 2). This result came as a surprise as it was expected that some amount of DNA molecules would remain stuck in the filter and would not elute in the buffer solution. This result is important as it means that no factor of filter retention will need to be accounted for in the quantification of DNA test particles in future studies. 
All filter extraction studies were repeated three times over multiple days to insure repeatability. Additionally, each individual sample was run in PCR in triplicate in order to produce statistically significant results.

Table 2. Filter extraction efficiency summary for the tested DNA template.

\begin{tabular}{cccc}
\hline \multicolumn{4}{c}{$\begin{array}{c}\text { Results: DNA Recovery for Three Filter Types } \\
\text { (\%, mean } \pm \text { one standard deviation) }\end{array}$} \\
\hline Simulated Masses on Filter & Teflon Filter & Glass Fiber Filter & Polyester Felt Filter \\
$10 \mu \mathrm{gg}$ & $104 \pm 11$ & $109 \pm 21$ & $111 \pm 13$ \\
$100 \mu \mathrm{gg}$ & $106 \pm 8$ & $95 \pm 9$ & $97 \pm 10$ \\
$1 \mathrm{mg}$ & $104 \pm 9$ & $105 \pm 9$ & $101 \pm 10$ \\
\hline
\end{tabular}

Some of the recovery experiments yielded average recovery rates above $100 \%$ however, all average recoveries are within one standard deviation of $100 \%$. The recoveries that yielded above $100 \%$ may be due to the general lack of precision in the sample preparation and/or process of qPCR. Additionally, these measurements of greater than $100 \%$ recovery may be due to a lack of a robust data analysis technique.

\section{New Skills and Knowledge}

Much of my lab time this summer was spent learning about and running qPCR.

Prior to this summer, I was familiar with the process of qPCR, but had never practiced it.

This experience has given me a

much greater understanding of

qPCR and in particular some of the

data analysis issues. In qPCR there

is an issue of where to draw the

cycle threshold line with which to

calculate the initial number of DNA
Figure 4: Full PCR amplification curve with cycle threshold drawn in for primary fluorescence growth curve analysis.

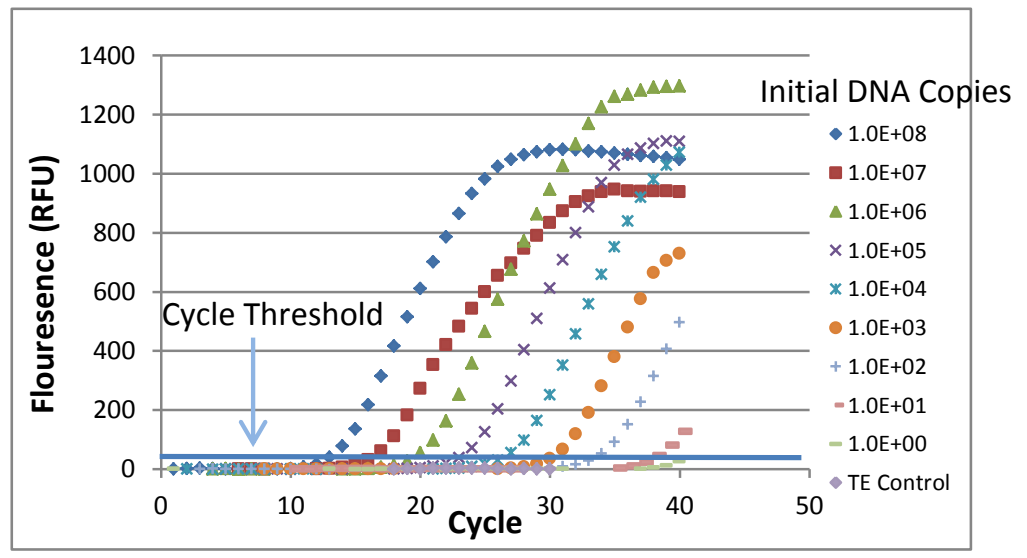


copies that were in the starting sample. The operating manual of the Smart Cycler used in our experiments offers two options for analyzing the fluorescence growth curve ${ }^{2}$. One option is the primary fluorescence growth curve and the other is the $2^{\text {nd }}$ derivative of the fluorescence growth curve. When analyzing the data using the primary growth curve, the signal is counted when the fluorescence level crosses a set boundary above the background fluorescence (Figure 4). This approach can achieve a more sensitive detection limit; however it is more affected by noise in the data and variance in reaction efficiencies. When analyzing the data using the $2^{\text {nd }}$ derivative of the primary fluorescence growth curve, the signal is counted when the $2^{\text {nd }}$ derivative of the primary fluorescence growth curve crosses a set boundary above the background. This analysis is potentially more reproducible because the $C_{t}$ is determined by the shape of the growth curve, therefore including more data points. Additionally, it is independent of the magnitude of the fluorescent signal. The $2^{\text {nd }}$ derivative data analysis has also been described as more accurate compared to primary growth curve analysis according to Luu-The et al. ${ }^{3}$ For our data analysis we looked at both the primary curve analysis and the $2^{\text {nd }}$ derivative analysis, but selected the $2^{\text {nd }}$ derivative analysis for its increase reproducibility. Yet another type of data analysis called 'global fitting' is explained by Carr and Moore $(2012)^{4}$. This more robust quantification uses the entire reaction profile and takes advantage of the brighter and less noisy fluorescence signals which occur later in the reaction. This is likely the ideal way to analyze our PCR data and this technique will likely be explored in future work.

In addition to learning new techniques while working on our project, I also attended many lectures. The DHS HS-STEM program had its own weekly lecture 
series, giving me exposure to the many homeland security related areas of research that are currently being pursued at the Lawrence Livermore National Laboratory. Additionally, I attended lectures held the Biosciences and Biotechnology Division, Condensed Matter and Materials Division and the High Energy Density Physics Division. I also had the privilege of touring the Terascale Simulation Facility, the National Ignition Facility, the High Explosives Application Facility and the Center for Accelerator Mass Spectrometry and saw first-hand some of the top science research facilities in the world. All of these experiences gave me an inside view of life working at a national lab which I will elaborate on more in the following section.

\section{Personal Impact}

This summer's experience showed me what it is like to perform research at a national laboratory. Having done research at my home institution, I noticed three key things that make research at LLNL very different from what is done at a college or university. Those key differences are in the people who work there, the type of projects they undertake and the resources available to them. This summer I met some very smart and accomplished researchers whom I wish to emulate in both intelligence and achievements. The major contributors to the project I worked on who I interacted with all had or are on their way to having their Ph.D.'s in the chemical sciences. My experience working with them has helped me to solidify my desire to earn a Ph.D. in chemistry. Additionally, the satisfaction they expressed with their careers has led me to strongly consider pursuing a career at a national laboratory.

The second distinguishing factor of work at a national lab is the projects that are undertaken. As research at LLNL is primarily funded through the DOE, DOD and DHS, 
the projects they undertake are naturally geared towards fulfilling the goals of these sponsors. Therefore, much of the research is performed with specific applications in mind. One benefit of doing application based research is that for many projects, the implementation of scientific discovery is extremely accelerated. Work that is performed with predetermined goals and set within specific time frames is often more exciting as it instills urgency and importance. The research that is done at a national lab has the added benefit of informing policy and ensuring the health, safety and security of the nation.

The third major factor that makes working at a national lab different is the resources available to the researchers, which differ from the private sector primarily in scale. Government funding increases the scope of potential topics and allows large scale issues in science to be undertaken. Additionally, researchers at a corporation may be limited in their scope of research if their achievements will not quickly turn a profit for their company. Government funding allows the pursuit of important topics in science that may not be immediately salable. Another outstanding feature of working at a national lab is the pool of expert peers all within a tight circle. Information about cutting edge research is spread quickly through the close proximity of researchers and plentiful lecture series. All of these factors are important in my excitement and anticipation to return to work at a national lab next year.

\section{Research ideas contributing to DHS}

Biological threats will always exist in our world, whether they are intentional or unintentional, malicious or not. Research and development should continue in the areas of detection and mitigation of biological threats. In choosing which areas to focus our 
efforts it will be important to think long term and in turn, move in the direction of developing more robust automated processes. Automated processes will be one of the best places to look for long term solutions to the detection and mitigation of biological threats. Along the same line of thinking forward, it is important for the DHS to continue to engage young people through outreach and internship programs. Bringing awareness of national security issues to young scientists and innovators is one of the best ways to continue innovation into the future.

\section{Acknowledgements}

I would like to thank the DHS HS-STEM program for providing me with the opportunity and the funding for my internship. I would also like to thank the members of the aerosol test particle team: Ruth Udey, Elizabeth Wheeler, Sarah Stephenson and George Farquar who made my internship experience enjoyable and rewarding.

Additionally, I would like to thank the Department of Energy and Lawrence Livermore National Laboratory for hosting me. This work was performed under the auspices of the U.S. Department of Energy by Lawrence Livermore National Laboratory under Contract DE-AC52-07NA27344. LLNL-TR-571912.

\section{References}

${ }^{1}$ Cornett, James B. and Gerald D. Shockman. "Cellular Lysis of Strptococcus faecalis Induced with Triton X-100.” Journal of Bacteriology. 1971, 108(1):545. Web. 07 Aug 2012. < http://jb.asm.org/content/108/1/545.full.pdf+html>

${ }^{2}$ Cephid. Smart Cycle Operator Manual. 2001. Print

${ }^{3}$ Luu-The, Van, Nathalie Paquet, Ezequiel Calvo and Jean Cumps. "Improved real-time RT-PCR method for high-throughput measurements using second derivative calculations and double correction." BioTechniques 38:287-293. February 2005. Web. 07 Aug. 2012.

${ }^{4}$ Carr, Ana C., and Sean D. Moore. "Robust Quantification of Polymerase Chain Reactions Using Global Fitting." National Center for Biotechnology Information. U.S. National Library of Medicine, 31 May 2012. Web. 02 Aug. 2012. <http://www.ncbi.nlm.nih.gov/pmc/articles/PMC3365123/?tool=pmcentrez>. 